\title{
RESENHA
}

\section{GRUPOS POPULARES BRASILEIROS: UMA COMPREENSÃO ACERCA DE SUAS DIVERSAS FORMAS DE PARTICIPAÇÃO POLÍTICA A PARTIR DA OBRA “ETNOGRAFIAS DA PARTICIPAÇÃO"}

\author{
BRAZILIAN POPULAR GROUPS: AN UNDERSTANDING OF VARIOUS \\ FORMS OF POLITICAL PARTICIPATION IN THE WORK \\ "ETHNOGRAPHIES OF PARTICIPATION
}

\begin{abstract}
Alânia Magalhães ${ }^{1}$
RESUMO

O presente trabalho tem como objetivo discorrer sobre a coletânea Etnografias da Participação analisando os artigos presentes na obra, organizada por Claudia Fonseca e Jurema Brites. Para enriquecer o estudo acerca dessa obra, fez-se necessário o acréscimo de conceitos estabelecidos por outros autores, tais como Dumont e Duarte et al., que, de forma inusitada, clarificam as noções de desigualdade presentes em Etnografias da Participação. De um modo geral, conclui-se que os artigos reunidos na obra em análise não pretendem defender a conversão dos grupos populares a um modelo preestabelecido de cidadania. Esses artigos acabam por evidenciar que o problema encontra-se em um sistema injusto e desigual, e não nas expressões políticas dos pobres.
\end{abstract}

Palavras-chave: Grupos populares. Política. Cidadania.

${ }^{1}$ Mestranda do Programa de Pós Graduação em Ciências Sociais da Universidade Federal de Juiz de Fora (UFJF). Possui interesse em questões como: desigualdade, estratificação social, desigualdade racial na educação, políticas públicas, subalternidade, sociologia da educação, classes populares, religiosidade. 


\section{ABSTRACT}

This paper aims to discuss about the collection Ethnographies Participation analyzing the articles presented in the book, organized by Claudia Fonseca and Jurema Brites. To enrich the study of this work, it was necessary the addition of concepts established by other authors, such as Dumont and Duarte et al. in unusual ways that clarify the concepts of inequality present in Ethnographies of Participation. In general, it follows that the articles collected in the work under review does not intend to defend the conversion of popular groups to a predetermined model of citizenship. These articles show that eventually the problem lies in an unequal and unjust system, not the political expressions of the poor.

Keywords: Popular groups. Political. Citizenship.

O presente trabalho tem como objetivo discorrer sobre a coletânea Etnografias da Participação, analisando os artigos presentes na obra, organizada por Claudia Fonseca e Jurema Brites. Para enriquecer o estudo acerca dessa obra, fez-se necessário o acréscimo de conceitos estabelecidos por outros autores, tais como Dumont e Duarte et al., que de forma inusitada, clarificam as noções de desigualdade presentes em Etnografias da Participação.

Inicialmente é possível afirmar que o escopo da coletânea em análise é demonstrar e compreender as diversas formas de participação política realizadas entre grupos populares brasileiros. Em Etnografias da Participação, o emprego de autores que desmistificam os princípios etnocêntricos de uma teoria moderna que pretende englobar todos num modelo de cidadania preestabelecido, possibilita a apreensão de modos de vida de certas categorias sociais ao recusar a perspectiva dominante e aceitar à ótica dos dominados.

Estabelece-se, assim, uma "tentativa de ver outros sistemas de baixo para cima" (FONSECA; BRITES, 2006), mesmo que nessa experiência sejam apresentados processos de participação política em condições de subalternidade. Afinal, em um país como o Brasil, onde emerge uma imensa pobreza e desigualdade, muitas vezes estas formas de participação aparecem entre as classes populares como as únicas possíveis.

Desta maneira, na coletânea em análise, são ressaltadas as especificidades dos grupos populares, não deixando escapar elementos que apresentam suas características em detrimento de uma lógica que explica a ação destes como mero resultado de influências da cultura dominante ou como anacronismo político. Assim, as classes subalternas não são vistas como degeneradas, e sim como grupos que têm positividade em suas formas culturais.

A obra reúne artigos que estabelecem conexão entre a vida cotidiana dos setores populares e forças do nível macro, como o Estado, partidos políticos etc. Os textos da coletânea observam a sociedade contemporânea em inúmeras cadeias de discussão, apresentando visões de mundo distintas da lógica racionalista.

De forma introdutória, Claudia Fonseca apresenta seu texto "Classe e recusa etnográfica", no qual descreve a dupla preocupação - por um lado, a de uma antropologia 
que se define pelo método etnográfico e, por outro, de um enfoque analítico que coloca classe, ao lado de gênero, geração, etnia e nação como categoria de relevância fundamental para a compreensão da sociedade contemporânea". (FONSECA; BRITES, 2006, p. 13).

Essa dupla preocupação de Fonseca fez com que se reúnam nesta coletânea, artigos que enfocam o trabalho cuidadoso de campo para compreender as diversas formas de participação política em variados contextos com a pretensão de entender outros modos de vida através do confronto com o diferente e ignorar a utilização de conceitos preestabelecidos antes da pesquisa de campo. Fonseca afirma que, em "Etnografias da participação", classe é colocada junto com gênero, etnia e geração, pois são fatores organizativos de ideias e comportamentos na sociedade contemporânea.

Nesses termos, pode-se observar que a coletânea em questão, foi estruturada em quatro temas. Em primeiro lugar, o debate é travado com o tema $\mathbf{O}$ antropólogo na política,; a segunda parte da coletânea relata Etnografias do poder, a terceira parte salienta tanto o cotidiano quanto as representações e práticas políticas dos setores populares, e é intitulada $\mathbf{O}$ popular na política; a quarta e última parte tem por título Espaços de negociação da cidadania.

Com o tema $\mathbf{O}$ antropólogo na política, o debate é travado através de dois textos, o primeiro de Christine de Alencar Chaves - "Os limites do consentido" - e o segundo de Ana Guglielmucci e Santiago Álvarez - "Los Rituales de la impunidad en Argentina: comensalidad y complicidad" -. Tais textos problematizam a atuação do antropólogo ao descrever os investigados.

O primeiro texto de Christine de Alencar Chaves ("Os limites do Consentido"), voltase para as diferenças internas do país e evidencia os desafios enfrentados pelo antropólogo nos questionamentos dos sujeitos sociais que toma por objeto de pesquisa. Com base nessa perspectiva, este trabalho apresenta seus limiares.

Durante a pesquisa, foi acompanhado um evento singular, a Marcha Nacional, a exemplo da ação política do MST, como forma de pressão sobre o Estado para consecução de objetivos do movimento. Observou-se, assim, o impacto que o movimento realizava sobre a sociedade e a incidência que estava obtendo nos meios de comunicação. A força que motivava a ação dos sem-terra era advinda do impacto social e da capacidade de mobilização que obtinha.

O movimento realizou-se à custa de sacrifício pessoal, coletivo e público, pois a Marcha Nacional exprimia as contradições do próprio MST enquanto organização coletiva. Nesse sentido, surge a dúvida se a etnografia deve retratar os conflitos internos do movimento, pois, muitas vezes, o antropólogo está nos limites do consentido, e não pode revelar alguns fatos da pesquisa etnográfica se estes não forem favoráveis a imagem do grupo investigado.

Já no texto de Ana Guglielmucci e Santiago Álvarez (“Los Rituales de la impunidad en Argentina: comensalidad y complicidad"), observa-se a análise de atos ritualizados de solidariedade considerados próprios da cultura argentina e a descrição de redes de cumplicidade e impunidade que constituíram o silêncio sobre o caso do "massacre de Margarita Bélen", ocorrido na província do Chaco durante a última ditadura militar argentina (19761983). 
A partir da análise dos fatos que envolveram o massacre, é possível reconstruir parte dos mecanismos que produzem cumplicidade, silêncio e impunidade. O asado criollo, em um contexto onde militares, autoridades judiciais, provincianas e municipais expressavam relações de poder, servia para "domesticar" a violência e subordinar as autoridades ao poder militar.

Nota-se que rituais como esse são conhecidos universalmente como importantes mecanismos de consolidação da solidariedade grupal, pois durante a comida não são expressos fatores como diferenças e hostilidades, o que ocorre é uma relação grupal, na qual são compartilhadas as mesmas perspectivas. Dessa forma, durante a ditadura na Argentina, a participação em atividades coletivas era parte da criação e manutenção de redes de cumplicidade e solidariedade entre pessoas de diferentes hierarquias.

A análise deste caso permite ao antropólogo conhecer a dinâmica de Estado na Argentina, explorando relações de solidariedade entre os representantes do Estado, do poder judicial e do mundo dos negócios. Além disso, ajuda na compreensão de uma prática social construída através do silêncio, demonstrando questões relativas ao trabalho do antropólogo e seu compromisso com a objetividade quando analisa questões problemáticas e atuais em sua sociedade.

Diferentemente, a segunda parte da coletânea relata Etnografias do poder e configura um bom exemplo para se compreender a lógica das classes subalternas, já que descrevem a relação entre forças do nível macro e setores populares.

O texto de Delaine Martins Costa, uma etnografia realizada na Câmara Municipal do Rio de Janeiro entre 1997-2000, apresenta modelos de atuação dos vereadores em uma tentativa de interlocução com o eleitorado. Os vereadores incorporam à sua prática o termo "participação popular", utilizando-se de encaminhamentos formais e informais das demandas das classes populares para o poder Executivo, e praticam, assim, ações de prestação de serviços.

Como o Estado não se faz presente, esses serviços, em sua maioria de caráter filantrópico, problematizam concepções diferenciadas de democracia e acentuam a distância entre democracia como ideal e sua real implementação. A questão é que, diante o universo dessas pessoas, esse tipo de "participação popular" se apresenta como única possibilidade de exercício da "democracia".

A chamada participação popular é aqui um termo ambíguo, disputado por diferentes segmentos sociais, tende, assim, a ser reconhecida pelos agentes políticos que a valorizam; os vereadores que a empregam e que veem nesta uma possibilidade de investimento de capital político e interlocução com a população. Em suma, as representações deste termo poderiam apenas ser compreendidas como expressão de práticas politiqueiras ou populistas. No entanto, é necessário refletir sobre o cotidiano dos setores populares, nos quais a busca por prestação de serviços é uma forma de garantir direitos sociais para o maior número possível de pessoas.

Sobre as outras discussões que exemplificam o tema "Etnografias do poder", observa-se também a abordagem de Francisco Pereira Neto sobre o tema da Assistência Social em Porto Alegre. Esse trabalho tenta compreender os processos sociais por onde passa a construção da solidariedade na sociedade atual. Dessa forma, é necessário analisar princípios que gerem processos de solidariedade social, interessados nas interfaces entre di- 
mensões políticas e religiosas A perspectiva adotada pelo autor propõe a abordagem da relação dos espaços políticos no campo da assistência com outros não necessariamente políticos.

O autor enfatiza a necessidade de reflexão sobre os desdobramentos políticos e religiosos na sociedade civil e afirma que, na realidade brasileira, os sentidos religiosos permeiam o imaginário social. Demonstra que a solução dos problemas sociais no meio globalizado encontra-se na capacidade da sociedade incutir a "responsabilidade social do capital" nas elites econômicas. Neste aspecto, é pertinente a avaliação sobre a incapacidade do Estado de gerar uma política de proteção social eficiente.

Assim, especialmente em Porto Alegre, compreende-se que as questões relacionadas ao campo da assistência social congreguem com os elementos da caridade religiosa. A aproximação entre os domínios da religião e da política é bem estruturada, ocorrendo a absorção de projetos políticos da prefeitura por entidades de assistência que possuem procedência religiosa.

Nesse contexto, considera-se que os católicos e os protestantes convivem com os ideais de secularização e reconhecem a pertinência dos princípios administrativos implantados pela prefeitura. Entretanto em alguns casos os grupos religiosos tendem privilegiar práticas personalistas, debilitando o estabelecimento de critérios democráticos. Nesse caso, o autor admite limites ideológicos entre o espaço religioso e o político e afirma que a ação dos agentes religiosos sempre estará sujeita a um princípio personalista, mesmo na legitimação de questões de domínio público, afinal existe neste meio uma falta de separação entre as esferas do público e do privado.

Seguindo a perspectiva da segunda parte da coletânea, o trabalho de Arlei Sander Damo, sobre o orçamento participativo (OP) em Porto Alegre também se enquadra como exemplo de análise da relação entre os setores populares e forças do nível macro. Nesse artigo, é sugerido que mesmo em casos de democracia participativa nem sempre é possível que a identidade popular alcance os objetivos do governo. O que ocorre é que o OP mantém-se combativo ao clientelismo, ao patrimonialismo, mas no processo de concretização tais pressupostos conflituam com as expectativas das lideranças populares.

Para captar os sentidos da participação mais ampla da população, o trabalho privilegiou as instâncias onde ocorre a participação mais intensa das comunidades: fóruns, e plenárias regionais. Os fóruns são, na verdade, uma espécie de curso prático de cidadania, nos quais se aprende como funciona o OP. Isso inclui o domínio de um léxico específico próprio aos liames da burocracia, da democracia, da participação cidadã e da cultura letrada. Neste contexto, o verbo "demandar" se contrapõe ao verbo pedir, assim como priorizar se contrapõe a apressar. A aposta nessas perspectivas faz da OP um dispositivo de enfrentamento ao clientelismo e ao patrimonialismo. Por esta razão, demandar e priorizar, entre outras expressões, são carregadas de valor e não apenas meros termos técnicos.

Em suma, muito mais que o dilema entre democracia participativa e representativa o OP dramatiza os significados da participação e da legitimidade de seus líderes, sejam eles representantes do poder público ou das comunidades. Em suas formas de se firmar frente à comunidade, muitas vezes os líderes realizam intervenções que podem ser vistas como populistas ou oportunistas, todavia estas são apenas uma forma verossímil de expressar o drama da comunidade. O OP é um espaço de produção cultural, onde são tencionadas 
desde a própria noções de participação até as definições de status, autoridade e reciprocidade entre os cidadãos e o Estado. Sendo neste aspecto inadequado afirmar que a participação no OP conduz à supressão de práticas arcaicas, como clientelismo e patrimonialismo, e conduz à racionalidade moderna, mesmo sendo um processo pedagógico para o cidadão participante. Enfim, também neste caso é salientado que alterações processuais não implicam em verdadeiras mudanças culturais.

Outro tema extraído da obra Etnografias da Participação, que salienta de forma clara tanto o cotidiano quanto as representações e práticas políticas dos setores populares, está na terceira parte, intitulada "O popular na política". Nesta parte, ocorre uma tentativa de refutação às perspectivas racionalistas que estigmatizam as ações dos grupos populares, como, por exemplo, de alienação e ignorância.

Isso está bem representado no caso de empregadas domésticas, vistas por Jurema Brites em uma pesquisa etnográfica no Espírito Santo entre os anos de 1995 e 1998. Nesta etnografia, enquanto os estudiosos denunciavam um sistema de dominação baseado em relações clientelistas, era evidenciado que as empregadas encontravam benefícios neste tipo de relação. A autora demonstra que, no contexto social e econômico dessas trabalhadoras, o serviço doméstico torna-se opção com possibilidades e vantagens inexistentes no mercado formal.

Em meio a essa discussão, a pesquisa evidencia que as vantagens demonstradas pelas domésticas coincidiam com o que os pesquisadores acreditavam ser a as raízes da subordinação entre o serviço doméstico. Na verdade, os relacionamentos clientelistas com os patrões eram a única forma que as empregadas tinham para tirar proveito daquela situação. Durante a pesquisa, em uma tentativa de compreensão da cultura popular, são utilizados conceitos como bilinguismo e a análise de teóricos, como S.Colen, E.P.Thompson e J.Scott.

A opção por voltar aos dados procurando entender as políticas que tentam tirar as empregadas das relações clientelistas e colocá-las dentro do mundo profissional moderno comprova que, nas perspectivas modernas, a relação entre patrões e empregados definese por compromissos contratuais. Em certa medida, o código contratualista exime os patrões de comprometimento com as diferenças sociais. Dessa forma, na perspectiva dessas mulheres, as relações paternalistas são mais vantajosas, já que possibilita a tolerância de muitos patrões com pequenos furtos das empregadas e permite a recorrente doação de objetos por parte de patroas que não são avarentas e mesquinhas.

Neste contexto, é revelado o caráter lúcido e moderno das práticas dessas empregadas, que acabam por cumprir o processo de participação política, mas em condições de subalternidade.

Outro exemplo de acesso à dinâmica política dos grupos populares está presente no artigo de Antonádia Monteiro Borges (Barraco: Etnografia dos meios e modos de vida no Recanto das Emas). Neste trabalho, por meio da prática etnográfica, a autora descreve o cotidiano de habitantes de um assentamento do Distrito Federal, tomando como exemplo o caso de três mulheres que vivem no Recanto das Emas.

Compreende-se, nesse texto, que a maneira como as pessoas estudadas ordenam suas experiências está relacionada à gênese do local em que vivem e ao processo social 
que implica essa política habitacional. A forma de se organizar, para viver em um lote onde há outras casas, traduz-se num modo de vida peculiar; além disso, as concepções dessas pessoas sobre o signo barraco inserem a relevância social de conceitos nativos.

O barraco representa o universo onde os objetos circundam a vida dos moradores, pois toda a gana por objetos revela-se gramatical para a efetuação de troca. Neste meio, as pessoas se reúnem para cozinhar juntas ou para dividir algo que alguém recebeu. Em meio às afirmações, surge a noção de que existe um valor ao se compartilhar algo, ou seja, através da troca estabelece-se um elo entre partes assimétricas e a troca mesmo que, realizada entre partes simétricas, se estabelece pela diferença, que se expressa no fato de alguém ter para dar e alguém precisar. Sendo o denotador da troca entre essas pessoas a pedição.

No mundo dos barracos ocorre o exercício constante de troca, mas quem mora em casa participa de outro circuito desse procedimento. Quem tem casa dá para quem pede, quem tem casa não divide o lote com mais pessoas e, acima de tudo, quem tem casa tem muro. Mas embora sejam diferentes entre si, o mundo dessas pessoas se cruza.

$\mathrm{Na}$ verdade, essas pessoas fazem parte de um único mundo. Apesar das distinções cada uma delas obedece a uma lógica de troca definida pela pedição. O lugar onde cada uma dessas mulheres vive apenas irá indicar diferentes modos de relação política, que cada uma mantém com o governo. Assim, é demonstrado que sobre a compreensão antropológica pode-se relevar práticas clientelistas decorrentes da luta por moradia e refutar considerações sobre ignorância e alienação dessas pessoas.

Outro artigo presente nessa sessão que se propõe a tratar de temas como clientelismo e cidadania, entre os grupos populares, é o trabalho de Pablo Semán (Las Formas políticas populares: Mas alla de los dualismos). Nesse trabalho, Semán pretende fazer um questionamento sobre o papel político de Margarita e sua inserção na rede clientelar. A análise sobre Margarita possibilita a compreensão da singularidade política dos setores populares em Buenos Aires, aferindo discussões acerca do conceito de clientelismo.

O autor utiliza para isso, distanciamento das teorias holísticas dominantes e das concepções que descrevem a personagem a partir da simples carência de cultura política moderna. Em suma, nessa análise, a referência ao caso de uma mulher inserida em redes clientelistas, religiosas e políticas ajuda a tornar evidentes as ambiguidades em torno das noções sobre política. A posição de Margarita na rede era tanto como doadora quanto como receptora de bens, pois ela também obtinha favores destinados a ela e sua família. $O$ autor enfatiza em seu argumento a crítica de Auyero à noção de clientelismo, onde é demonstrado que esta prática não se encontra em distribuição de alimentos, mas sim em redes de relações e representações culturais construídas diariamente entre políticos e clientes.

Nos termos de Semán, Margarita apresenta uma versão de moralidade entre favorecedores e favorecidos. Dessa forma, o autor apresenta a ideia de que o clientelismo seja um ponto de vista pré-construído e traz à discussão a possibilidade de pensar essas representações como uma pauta de organização política dos setores populares.

Neste aspecto, outro tema é inserido na terceira parte como exemplo da expressão identitária de setores populares. O trabalho de Eloísa Martins ("Cumbia, birra, faso"), em torno das possibilidades políticas de um gênero musical na Argentina contemporânea, des- 
creve um gênero musical argentino, a cumbia villera, que surge na segunda metade dos anos 1990, revelando o mundo dos jovens mais pobres de Buenos Aires.

A cumbia villera não maquia os traços da pobreza. Nas letras e no estilo, assume o conteúdo de classe que não se reduz ao étnico, representa além do negro o villero. Nestes termos, o artigo de Eloísa Martín discute as possibilidades políticas que esse estilo musical apresenta na Argentina contemporânea.

A autora demonstra que, sob um contexto onde as vias tradicionais centradas na escola e no trabalho não levam os jovens para ascensão social, consolidam-se outros meios de subsistência entre os jovens dos setores populares na grande Buenos Aires: o roubo, o tráfico, a mendicância e os bicos. Os villeros em termos de Focault (1989) colocam suas experiências em contraste aos aparelhos do poder disciplinador: a escola e o trabalho. Positivam uma linguagem não escolarizada e, em seu cotidiano, o trabalho deixa de ser atividade legítima para subsistência. Seus erros gramaticais representam a intenção de ruptura, deboche e de desafio, o trabalho não é mais fonte de sustento, para os villeros é forma de exploração e atividade de otários.

Nas letras das cumbias questiona-se o papel do dinheiro como mediador das relações sociais. Seu papel é questionado, pois não compra a amizade, não ganha o amor de uma mulher, não faz de alguém homem, enfim corrompe os valores villeros. DesSa forma, o valor do dinheiro não se mede pela quantidade, mas pelo modo como foi obtido.

Nota-se também que a mídia tem papel ativo na definição e controle dos conteúdos da cumbia villera, ao mesmo tempo dando espaço para este ritmo musical aparecer e fazendo controle ao defini-lo como produto de marginais. De forma geral, varias reportagens a criticam por fazer apologia ao crime, por causa dos temas de roubo e uso de drogas nas letras etc.

Em suma, os villeros, realizam uma crítica que não é uma resistência, e nem apenas forma de reação contra a cultura hegemônica. Nas músicas eles não pedem trabalho, não reclamam justiça social, apenas positivam uma forma de experienciar o mundo, que expressa ruptura com o jogo disciplinador da escola e do trabalho e revela um universo distinto do dominante.

Para encerrar a coletânea, a quarta e última parte, intitulada "Espaços de negociação da cidadania", traz a noção de que os atos dos grupos populares devem ser lidos dentro do contexto no qual estão inseridos. Os três textos apresentados nessa parte demonstram a cidadania como espaço de negociação.

O primeiro texto, descrito por Paula Camboim de Almeida, tem como tema "O Discurso médico sobre a gravidez na adolescência e a construção de um problema social". A autora tenta ver o discurso da gravidez na adolescência sobre outra ótica, ou seja, tenta trazer para a análise a visão das próprias adolescentes sobre a gravidez nessa fase da vida. Remetendo ao discurso de Cláudio Fonseca, pode-se observar nesse artigo mais uma tentativa de ver a visão do "outro" através do trabalho de campo extremamente cuidadoso, apenas dessa forma pressupostos etnocêntricos são colocados de lado.

O objetivo da autora com essas implicações não é fazer uma apologia da gravidez na adolescência, mas problematizar a maneira como essa questão vem sendo tratada. Para isso demonstra que, em geral, a questão é tratada como precoce, indesejada, não planeja- 
da. Entretanto, a partir do convívio com as pesquisadas, em bairros populares de Porto Alegre e Santa Cruz do Sul, não reconheceu, na visão dessas jovens, a maternidade adolescente como um problema.

Com essas premissas, Paula Camboim passa a analisar de que forma a gravidez na adolescência se constrói como um problema social no discurso médico. Nesses termos, é afirmado que essas dimensões fazem da gravidez na adolescência um problema social e constroem um processo que torna pública uma questão antes considerada particular. Há tempos, uma mulher engravidar aos 16 anos era habitual. Assim, é colocado que o discurso médico é uma das formas de enunciar publicamente a gravidez na adolescência como um problema social.

Com isso, a pretensão neste artigo é mostrar a descontinuidade entre o discurso médico e o das jovens pesquisadas para que políticas públicas passem a considerar a alteridade. Afinal, a compreensão de outras perspectivas é fundamental tanto para a formulação de políticas públicas mais eficazes quanto para a negociação da cidadania.

Já o segundo artigo sobre "Espaços de negociação e Cidadania" aborda a relação familiar de mulheres parentes de presidiários em Charqueadas, no Rio Grande do Sul. A análise sobre esposas, mães e irmãs de presos demonstra como o aprisionamento masculino reflete nas relações familiares e de vizinhança dos agentes envolvidos neste acontecimento. Pertencer a uma família caracterizada pela experiência prisional faz com que essas mulheres sofram estigmas por parte dos atores a qual se relacionam. Essas mulheres são vistas por pessoas das agências estatais (funcionários da prisão, advogados, policiais etc.) como cúmplices ao mundo do crime. Dessa forma, ser "mulher de preso" carrega a responsabilidade de enfrentar as autoridades em busca dos direitos mínimos de seus familiares.

Assim, através do trabalho de campo é visto que nessa busca por direitos mínimos dos presos, essas mulheres passam por diversas humilhações. No entanto, esses desafios possibilitam o acúmulo de conhecimentos sobre participação política em assuntos que as beneficiam. Podemos considerar que na "caminhada" dessas mulheres para proteger seus maridos ocorre um processo de "cidadanização", que não se dá de forma passiva, pois as experiências anteriores permitem uma releitura por parte desses agentes.

De forma geral, essa análise comprova que a relação familiar dos homens ali aprisionados é marcada pela inserção política de suas mulheres, que fazem uma apropriação e releitura da cidadania tentando obter melhores condições para seus filhos, irmãos e maridos presos.

O último artigo da coletânea, também pertencente ao tema "Espaços de negociação e Cidadania", toma como objeto de estudo a ação política de mulheres idosas beneficiárias de um dispensário carioca. A autora Delma Peçanha Neves descreve o papel de mães ou avós no auxílio aos parentes impossibilitados de provisão autônoma. $\mathrm{O}$ artigo expressa a visão de mundo dessas mulheres, cujo exercício de reivindicação de recursos filantrópicos auxilia a unidade familiar.

A autora se depara com uma posição privilegiada por parte dessas idosas, já que elas aglutinam diversos recursos para prover a família, como: bolsas de alimentos redistribuídas por instituições filantrópicas, pensão ou aposentadoria, pensão continuada 
e posse ou aluguel de barracos em favelas. Na verdade, as idosas pesquisadas são beneficiadas por uma série de recursos que as diferem entre si mesmas. Muitas vezes esses recursos são obtidos por uma habilidade em demonstrar a carência e por disponibilidade em receber assistência, e essas habilidades, construídas historicamente, são transmitidas aos netos que acabam por ajudar na alocação de recursos para o bem-estar da família.

Entre outras habilidades dessas senhoras está o fato de não perderem oportunidades de aumentar a rede de redistribuição de recursos, pois as aberturas de relações são importantes para minimizar os efeitos da pobreza. Nesta lógica, os benfeitores utilizam-se dessas doações como forma de inserção ao universo moral validado na rede institucional de caridade. É como se os saberes dessas mulheres utilizados na busca pela sobrevivência familiar recriassem a dependência entre desiguais, de um lado os beneficiados que tentam acalentar a miséria, de outro lado os benfeitores que tentam se inserir no universo da caridade. Enfim, este artigo salienta o importante papel das práticas filantrópicas em que serviços de assistência social são inexistentes, porém a autora não deixa de exemplificar a "reprodução da desigualdade".

A partir do exposto acerca da coletânea Etnografias da Participação surge uma possibilidade de reflexão sobre os setores populares, sendo necessário considerar o papel realizado por estes diante da política dominante. Torna-se também indispensável o aprofundamento na análise sobre a inserção desses atores em práticas consideradas de cunho clientelista. Conclui-se, assim, que nessa coletânea é apresentada uma compreensão acerca da singular experiência política dos sujeitos das classes populares.

Observa-se que, para a consecução deste objetivo, fez-se necessário o distanciamento das teorias políticas dominantes e das concepções que descrevem as classes subalternas como desprovidos de cidadania e carentes de uma cultura política que despreza práticas arcaicas, como o clientelismo. Clientelismo, na obra organizada por Claudia Fonseca e Jurema Brites, é visto como realidade dependente dos contextos culturais.

Dessa maneira, é imprescindível remeter às teorias utilizadas por Semán, quando esse cita as noções de Auyero, autor que vê a pr'stica clientelista inserida em redes de relações e representações culturais construídas diariamente entre políticos e clientes. De forma geral, o clientelismo não existe como fim da cidadania e redução da dignidade política, e sim como relações que implicam uma moralidade específica que comunica patrões e clientes. Sendo assim, o termo clientelismo representa na obra em análise, a exemplificação da organização política dos grupos populares.

Esta coletânea opõe-se a interpretações que afirmam de maneira evolucionista a existência de ignorância nos atos políticos das classes populares. E, sob o impacto do desprestígio desse modelo e da e valorização da diferença, defende-se uma concepção positiva da cultura popular, tendo uma postura crítica diante as práticas de conversão dos diferentes.

A não adesão popular aos ideais de mudança não é interpretada como sintoma de alienação e falsa consciência. Na verdade, ocorre uma ambiguidade entre a legitimidade do discurso dominante e a legitimidade do quotidiano da população. Esta interpretação aponta para o que dizem Duarte et al., em seu trabalho intitulado Vicissitudes e limites da conversão à cidadania nas classes populares brasileiras. Para este autor, a problemática moderna existe devido aos impasses entre o projeto universalista de liberdade, igualdade 
e respeito, e a noção de preservação da diferença. Além disso, o paralelismo entre cidadanização e o processo de implantação do que Focault chamou de poder disciplinar nunca pode ser considerado completo, pois aponta na direção oposta à liberdade.

Neste aspecto, encontra-se um pensamento de certa forma análogo ao de Dumont em Homo hierarchicus: o sistema das castas e suas implicações, onde o autor afirma ser o ideal igualitário artificial. Em suas palavras "a igualdade só é boa quando combinada à liberdade e quando consiste de proporcionalidade, isto é, quando aplicada razoavelmente (talvez mais equidade do que igualdade)". (DUMONT, 1975, p. 60). Compreende-se que Dumont coloca o ideal igualitário como algo artificial. Para ele, é natural que os princípios hierárquicos englobem os agentes sociais e as categorias sociais. Paralelamente, os estudos de Duarte et al. (1986) acabam por definir esta mesma noção, pois expressam que o universo simbólico das classes populares contrasta com o das classes médias, no sentido que estas seriam individualistas, universalistas e igualitárias, enquanto as classes populares afirmariam valores hierárquicos. Essa posição combina a universalidade e a reciprocidade com o pressuposto de desigualdade geral, contraposto à ideia moderna de igualdade natural entre os homens.

Com esta perspectiva, o que se chama de clientelismo pode ser conhecido como uma forma de aliança que implica uma definição hierarquizada dos vínculos existentes na mesma. A aliança política trata-se de um jogo de reciprocidades pautadas por posições distintas que implicam no cumprimento de proteção pelos maiores e a lealdade dos menores.

Em suma, através da analise de Etnografias da Participação compreende-se que os agentes sociais aqui analisados entram em ação e omissão política a partir de uma perspectiva que se conjuga na teologia popular, e suas propensões ao clientelismo são efeito de sua autorrepresentação e de suas relações. Suas ações estão articuladas a partir dos efeitos de sua história, de seu cotidiano, de sua cultura.

Dessa forma, capta-se a possibilidade de positividade de experiências políticas que se desenvolvem fora dos marcos de ideal democrático dominante, pois é preciso que os conceitos de história, cotidiano e cultura sejam considerados no processo de apreensão das ações políticas dos grupos populares.

Assim, os artigos reunidos na obra organizada por Claudia Fonseca e Jurema Brites não pretendem defender a conversão dos grupos populares a um modelo pré-estabelecido de cidadania, pois, como consideram Duarte et al. ( 1993) essa conversão impõe limites. Acabam por evidenciar que o problema encontra-se em um sistema injusto e desigual, e não nas expressões políticas dos pobres. Além disso, demonstram que a tentativa de disciplinar as classes populares é de certa forma falível, pois não altera de forma verdadeira as condições de vida dessas pessoas, apenas camuflam a realidade. Nesse sentido, a contextualização da noção de cidadania é apresentada como necessária, pois, na verdade, as atitudes dos subalternos nada mais são que uma crítica ao sistema político dominante. 


\section{REFERÊNCIAS BIBLIOGRÁFICAS}

DUARTE, Luiz Fernando D. et al. Vicissitudes e limites da conversão à cidadania nas classes populares brasileiras. Revista de Ciências Sociais, v. 22, p. 5-19, 1993.

DUMONT, Louis. Homo hierarchicus: o sistema das castas e suas implicações. São Paulo: EDUSP, 1975. p. 4968.

FONSECA, Cláudia; BRITES, Jurema (Org.). Etnografias da participação. Santa Cruz do Sul: Edunisc, 2006. 